\title{
INDICADORES AMBIENTAIS: UM ESTUDO DAS PRÁTICAS QUE OS IMPACTAM EM COMPANHIAS DE PETRÓLEO
}

\section{ENVIRONMENT'S INDICATORS: A STUDY OF THE PRACTICES WHICH INCREASE THE ENVIRONMENTAL PERFORMANCE IN PETROLEUM CORPORATIONS}

\author{
Antonio Roberto da Silva ${ }^{1}$; Stella Regina Reis da Costa ${ }^{2}$; \\ ${ }^{1}$ Universidade Federal Fluminense- UFF - Niterói - Brasil \\ arsilva@petrobras.com.br \\ ${ }^{2}$ Universidade Federal Fluminense e Universidade Federal Rural do Rio de Janeiro - UFF/UFRRJ - \\ Niterói/Seropédica - Brasil \\ stellare@ig.com.br
}

\section{Resumo}

A pesquisa abrange a verificação do grau de evidenciação dos indicadores de sustentabilidade ambiental, selecionados para esse estudo (consolidado e por ano), divulgados por companhias de Petróleo. É apresentada também as principais práticas adotadas pelas companhias selecionadas para a pesquisa, que as levaram a uma provável melhoria do seu desempenho ambiental.

Palavras-chave: indicadores, sustentabilidade, petróleo.

\section{Introdução}

A pressão da sociedade civil sobre as práticas ambientais das grandes companhias dos setores como o de petróleo, químico e de mineração tem aumentado em todo o mundo e vem ganhando projeção na mídia e na consciência dos consumidores. Como decorrência deste processo e da percepção do impacto do atual modelo de desenvolvimento na qualidade de vida presente e a sua implicação para o futuro do ser humano, os consumidores, especialmente em países mais desenvolvidos, vem modificando seus critérios de escolha de marcas e companhias.

Como consequiência desses movimentos, diversas companhias petrolíferas passaram a valorizar a proteção ambiental em função de seu potencial de ganhos relativos: por um lado não poluir significa - além da evidente prática da cidadania e de uma ação politicamente responsável não ser multado, não ter sua fábrica fechada e não ter sua imagem manchada. Por outro lado, as companhias se deram conta de que a menor emissão de poluentes freqüentemente está associada à 
maior produtividade, melhor aproveitamento de recursos e eliminação de desperdícios, com vantagens operacionais e financeiras.

Algumas dessas companhias passaram a incorporar no seu planejamento o conceito de ecoeficiência: fazer ou produzir mais utilizando menos recursos, através de processos mais eficientes, focados na prevenção de poluição, que resultem em menor consumo específico de matéria-prima, água e energia, otimizando todo o processo produtivo e reduzindo o impacto ambiental.

Além disso, a implementação de melhores práticas de responsabilidade socioambiental por parte das companhias, também passou a ser reconhecida pelo mercado de capitais, que valorizaa de forma diferenciada os papéis dessas companhias que operam de forma sustentável. Em geral, a valorização está relacionada à redução de riscos de conformidade legal, a cuidados de gestão que reduzem a possibilidade de acidentes e à promoção e cuidados com os contextos da cadeia produtiva, os quais minimizam os conflitos socioambientais.

$\mathrm{Na}$ análise dos riscos, também se considera que os investimentos em meio ambiente e em responsabilidade social empresarial refletem a solidez da Companhia (só estão aptas a buscar o triple botton line - resultado financeiro, social e ambiental - as companhias que tem negócios sólidos, capacidade produtiva e organização).

Desta forma, o compromisso com a promoção da sustentabilidade ambiental impõe o conhecimento e o desenvolvimento de novos processos de apreensão da realidade, que permitam a percepção integrada dos diferentes fatores sociais, econômicos e ecológicos que determinam a qualidade ambiental.

A condução dessa perspectiva exige, entre outros mecanismos, a definição de indicadores que relacionem as condições de sustentabilidade ambiental com os diferentes setores da produção social. Essa demanda consta objetivamente da AGENDA 21, que determina que os países devam desenvolver sistemas de monitoramento e avaliação dos avanços, em relação ao desenvolvimento sustentável, através do uso de indicadores que meçam as mudanças nas dimensões econômica, social e ambiental.

Cientes do seu papel na contribuição para o desenvolvimento sustentável, as maiores companhias petrolíferas do mundo adotaram uma postura em sintonia com a AGENDA 21, implementando um conjunto de estratégias para o controle e a prevenção de impactos ambientais e sociais e com o estabelecimento de indicadores ambientais, que possam dar a medida do desempenho das suas atividades em matéria de sustentabilidade.

As discussões e avaliações, em torno desse tema são significativas. Os indicadores podem servir como mais um instrumento no equacionamento dos desafios impostos na busca do desenvolvimento sustentável, e refletem as práticas adotadas pelas companhias para assegurarem 
menos desperdícios, racionalização dos processos produtivos, ao mesmo tempo em que geram mais valor e conseqüentemente mais riqueza e mais lucro.

\section{Situação Problema}

A relevância da indústria do petróleo mundial está além de sua posição energética, pois impacta significativamente em outros segmentos da cadeia produtiva, influência esta que pode ser verificada em termos econômicos, políticos e financeiros.

O investimento estimado do setor para o período de 2001 a 2030 é de US\$ 3,04 trilhões distribuídos em: US\$ 2,18 trilhões para o segmento de exploração e produção (72\%); US\$ 395 bilhões para o refino (13\%) e US\$ 465 bilhões para os demais segmentos (15\%) (ARAGÃO, 2005).

Atualmente, as gigantes da indústria do petróleo disputam a primazia de possuir as melhores tecnologias de energia renovável e atingir as melhores marcas na redução de emissões numa tentativa de mudar sua imagem pública, desgastada por décadas na liderança na emissão de $\mathrm{CO}_{2}$, responsáveis por elevadas taxas de emissão de poluentes e incontáveis acidentes de grandes proporções.

Ao menos no plano da retórica, representantes desse setor, se esforçam em demonstrar que os custos associados à administração do passivo ambiental deixaram de ser vistos como um mal necessário para serem encarados como parte integrante do negócio.

Isso representa um importante passo, uma vez que obrigou as companhias a reconhecerem que não estão sozinhas e que elas não têm autonomia para decidir como e quando explorar os recursos de uma determinada região

Por outro lado, um dos principais instrumentos de gestão para o desenvolvimento da sustentabilidade das atividades das companhias, que de alguma forma impactam o sistema econômico, social e ambiental, são os indicadores. Os indicadores são instrumentos que visam simplificar, quantificar e analisar informações técnicas sobre determinada ação ou fato e são úteis para subsidiar tomadas de decisão no sentido de direcionar a atividade. Os indicadores de sustentabilidade são em si informação seleta e processada, cuja utilidade tem sido predefinida e sua existência justificada. Portanto, permitem a realização de uma análise eficiente da inter-relação entre as principais práticas de gestão ambiental adotadas pelas companhias de petróleo com a sociedade e, ao mesmo tempo, ancorá-la nas estratégias e atividades específicas, bem como permitem a comparação de desempenho entre sociedades sustentáveis industrializadas. 


\section{Objetivo}

O presente estudo tem como objetivo divulgar e analisar as principais práticas de gestão ambiental utilizadas por 8 companhias petrolíferas, signatárias do Global Reporting Initiative GRI, que levaram a melhoria do desempenho dos indicadores ambientais, divulgados nos seus relatórios de sustentabilidade no período de 2003 a 2007.

\section{Metodologia}

\subsection{Tipo de pesquisa}

Para classificar a metodologia da pesquisa utilizada para elaborar este artigo tomou-se como base a taxionomia apresentadas por Vergara (2004), que qualifica em relação a dois aspectos: quanto aos fins e quanto aos meios.

Quanto aos fins, a pesquisa foi exploratória, descritiva, a partir de estudo referencial, tendo como ferramentas: pesquisa do assunto desenvolvimento sustentável e indicadores de ecoeficiência, nos "websites" de companhias e entidades na internet, análise crítica da literatura e das informações obtidas, visando conhecer a evolução dos indicadores ambientais sustentáveis nas companhias de petróleo e gás.

Quanto aos meios, a pesquisa foi bibliográfica e documental. Bibliográfica, porque para a fundamentação teórico-metodológica do trabalho, foi realizada uma investigação nacional e internacional, em livros, dissertações, artigos de congressos, teses e publicações sobre desenvolvimento sustentável, sustentabilidade, indicadores, indicadores de gestão sustentável, e indicadores de sustentabilidade ambiental.

A investigação foi, também, documental, porque se valeu de documentos verificados nos sites públicos das companhias selecionadas, no período de 2003 a 2007. As informações obtidas foram consideradas fidedignas, visto que muitas são oriundas dos relatórios de comunicação das companhias e/ou dos relatórios anuais de sustentabilidade submetidos às companhias de auditoria, possibilitando, assim, sua utilização para a execução deste trabalho.

E finalmente, um estudo de casos múltiplos com 8 companhias do setor de petróleo e gás. Para Yin (2005), estudo de caso é uma investigação empírica que investiga um fenômeno contemporâneo dentro de seu contexto da vida real, especialmente quando os limites entre o fenômeno e o contexto não estão claramente definidos.

Segundo o autor, o mesmo estudo pode conter mais de um caso único. Quando isso ocorre o estudo utilizou um projeto de casos múltiplos. 


\subsection{Critérios para escolha das companhias e dos indicadores para a pesquisa}

Para definição e escolha das companhias verificadas, foi utilizada a lista das 100 maiores companhias de petróleo do mundo, publicada anualmente pelo anuário Petroleum Intelligence Weekly 2007. Os seguintes critérios de corte foram propostos e utilizados:

a) Da amostra inicial, foram selecionadas as 15 primeiras companhias listadas no ranking, , apresentadas na Tabela 1, que representam as maiores companhias do segmento petrolífero do mundo;

b) Utilização, pelas companhias selecionadas, das Diretrizes para Relatório de Sustentabilidade GRI na elaboração de seu Balanço Social e Ambiental, no período de 2003 a 2007, respondendo aos indicadores essenciais e adicionais e realizar auditoria externa das informações divulgadas;

c) Relatórios de Sustentabilidade dessas companhias, disponibilizados pela internet que continham o Sumário de Conteúdo da GRI.

Após verificação inicial e reaplicação dos critérios, além de se levar em conta a representatividade da amostra e dos recursos humanos e temporais para a pesquisa, foi definida a utilização de 8 companhias para estudo de caso múltiplo, que fazem parte da amostra inicial.

Tabela1: Ranking das 15 maiores companhias de petróleo do mundo

\begin{tabular}{|l|l|l|c|}
\hline Rank & \multicolumn{1}{|c|}{ Companhias } & \multicolumn{1}{c|}{ País } & Diretrizes do GRI \\
\hline 1 & SAUDI ARAMCO & Arábia Saudita & Não \\
\hline 2 & EXXONMOBIL Corporation & EUA & Sim \\
\hline 3 & NIOC & Irã & Não \\
\hline 4 & PDVSA & Venezuela & Não \\
\hline 5 & BP - Bristish Petroleum & Inglaterra & Sim \\
\hline 6 & SHELL - Royal Dutch Shell & Inglaterra e Holanda & Não \\
\hline 7 & PetroChina & China & Sim \\
\hline 8 & CHEVRON Corporation & EUA & Sim \\
\hline 9 & TOTAL - Total SA & França & Sim \\
\hline 10 & PEMEX - Petróleos & México & Não \\
\hline 11 & CONOCOPHILLIPS Company & EUA & Não \\
\hline 12 & SONATRACH & Argélia & Sim \\
\hline 13 & KPC & Kuwait & Não \\
\hline 14 & PETROBRAS S.A & Brasil & Rússia \\
\hline 15 & GAZPROM & &
\end{tabular}

Fonte: Adaptado da Petroleum Intelligence Weekly 2007 
Com base nos critérios supramencionados foram selecionadas as oito companhias para a pesquisa, por ordem alfabética:

- BP : Bristish Petroleum

- CHEVRON : Chevron Corporation

- CONOCOPHILLIPS: ConocoPhillips Company

- EXXONMOBIL: Exxon Mobil Corporation

- PEMEX: Petróleos Mexicanos

- PETROBRAS: Petróleo Brasileiro SA

- SHELL: Royal Dutch Shell

- TOTAL - Total SA

Não se buscou comparar o desempenho ambiental destas companhias ente si, uma vez que elas possuem processos e características distintas. Logo, as companhias foram analisadas individualmente, considerando a evolução do desempenho ambiental entre os anos de 2003 a 2007.

A próxima etapa foi a definição de critérios para a escolha de indicadores que pudessem apresentar informações sobre o desempenho ambiental das 8 companhias estudadas e que pudessem servir de plataforma para identificar as práticas adotadas para a melhoria do desempenho ambiental. A partir de critérios referenciados pela literatura, para esse segmento, foi constado que os indicadores relacionados ao consumo excessivo e não sustentável da água, energia, poluição de rios, mares e águas subterrâneas, efluentes líquidos industriais, contaminação de solos por operações industriais e depósitos de resíduos e poluição atmosférica são os que têm grande impacto ambiental, sendo, portanto, forçosamente, focalizados também pelas companhias de petróleo há pelo menos uma década.

Assim, considerando o nível de aderência dos indicadores ambientais utilizados e divulgados pelas companhias estudadas, e como signatárias do GRI, aplicam as Diretrizes do GRI para elaboração de seus relatórios de sustentabilidade, foram selecionados 6 indicadores demonstrados na Tabela 2, integrantes do conjunto de 30 indicadores indicados pelo GRI, para esse estudo. 
Tabela 2: Indicadores selecionados para pesquisa

\begin{tabular}{|l|l|}
\hline \multicolumn{1}{|c|}{ Indicador do GRI } & \multicolumn{1}{c|}{ Descrição } \\
\hline $\begin{array}{l}\text { EN3 - Consumo de energia direta discriminada por } \\
\text { fonte de energia primária }\end{array}$ & $\begin{array}{l}\text { Mede o consumo de fontes primárias de energia } \\
\text { direta pela Companhia relatora. }\end{array}$ \\
\hline EN8 - Total de retirada de água por fonte & $\begin{array}{l}\text { Identifica o volume total de água retirada de } \\
\text { qualquer fonte de água, quer seja diretamente } \\
\text { retirado pela Companhia relatora ou por } \\
\text { intermediários como empresas de abastecimento de } \\
\text { água. Isso inclui a captação de água para } \\
\text { resfriamento. }\end{array}$ \\
\hline $\begin{array}{l}\text { EN16 - Total de emissões diretas e indiretas de gases } \\
\text { causadores do efeito estufa, por peso }\end{array}$ & $\begin{array}{l}\text { Emissões de fontes que são da propriedade ou } \\
\text { terceiros da Companhia relatora, relacionadas a } \\
\text { combustão provenientes da queima de combustível } \\
\text { para gerar energia dentro dos limites operacionais e } \\
\text { as resultantes da geração de eletricidade, calor ou } \\
\text { vapor importados e consumidos. }\end{array}$ \\
\hline $\begin{array}{l}\text { EN20 - NOx, SOx e outras emissões atmosféricas } \\
\text { significativas, por tipo de peso }\end{array}$ & $\begin{array}{l}\text { Emissões atmosféricas que são reguladas por } \\
\text { convenções internacionais e/ou leis ou regulamentos } \\
\text { nacionais, incluindo aqueles mencionados em } \\
\text { licenças ambientais de operação da Companhia. }\end{array}$ \\
\hline $\begin{array}{l}\text { EN22 - Peso total de resíduos, por tipo e método de } \\
\text { disposição }\end{array}$ & $\begin{array}{l}\text { Identifica a quantidade de resíduos gerada pelas } \\
\text { operações da Companhia classificada por resíduos } \\
\text { perigosos e não perigosos. }\end{array}$ \\
\hline $\begin{array}{l}\text { EN23 - Número e volume total de derramamentos } \\
\text { significativos }\end{array}$ & $\begin{array}{l}\text { Identifica todos os derramamentos significativos } \\
\text { registrados e o volume desses derramamentos. }\end{array}$ \\
\hline
\end{tabular}

Fonte: Conjunto de Protocolos de Indicadores - GRI

Os dados desses indicadores foram coletados nos relatórios anuais de sustentabilidade das Companhias selecionadas, no período de 2003 a 2007, disponibilizados pela Internet, via site do GRI ou das companhias, sendo organizados em tabelas, e posteriormente analisadas individualmente, as principais práticas de gestão ambiental adotadas pelas companhias para a melhoria do desempenho dos indicadores ambientais.

\section{Resultados}

Com relação às melhores práticas adotadas individualmente pelas 8 companhias petrolíferas, para os a melhoria do desempenho dos 6 indicadores de sustentabilidade ambientais selecionados para esse estudo, no período de 2003 a 2007, os resultados são apresentados nas tabelas a seguir: 
Tabela 3: Resultado do indicador EN3- Consumo de energia direta discriminada por fonte de energia primária

\begin{tabular}{|l|l|}
\hline \multicolumn{1}{|c|}{ Empresa } & \% de Aumento (Redução) do Consumo \\
\hline BP & $(21)$ \\
\hline Chevron & 4 \\
\hline ConocoPhillips & 7 \\
\hline ExxonMobil & Não divulgado \\
\hline Shell & Não divulgado \\
\hline Total & $(13)$ \\
\hline Pemex & 6 \\
\hline Petrobras & 20 \\
\hline
\end{tabular}

Fonte: Adaptado do GRI-2008

Como observado na tabela 3 , das oito Companhias analisadas, apenas duas (25\%) apresentaram redução no consumo de energia, quatro (50\%) aumentaram e duas (25\%) não apresentaram o indicador conforme orientações contidas no Conjunto de Protocolos do GRI. Observa-se ainda, que a redução da BP (0,3 mil terajoules) refere-se ao período 2005 a 2007, vez que a Companhia não divulgou esse indicador nos anos de 2003 e 2004. De acordo com os relatórios de sustentabilidade, a BP atua sobre a eficiência energética nas áreas de exploração, produção, transporte marítimo e operações de refino, que requerem uma grande quantidade de energia.

A Companhia tem como objetivo melhorar constantemente seu negócio comercial mediante projetos de eficiência energética, sendo que a redução observada em 2006 e a manutenção dos níveis em 2007 foram alcançadas graças ao programa sobre eficiência energética de sete anos de duração, em que foram investidos US\$ 450 milhões, tendo iniciado em 2004.

Para a TOTAL, a eficiência energética é considerada uma das principais formas de combater as alterações climáticas. É também uma preocupação constante, não por ser um produtor de energia, mas também um grande consumidor.

Segundo a Companhia, foram criadas orientações comuns de gestão de energia aplicável em todos os seus negócios e estão sendo aplicados significativos gastos de capital para programas de redução de energia. Investimentos em Refinarias serão realizados nos próximos cinco anos, para a modernização da qualidade e na quantidade de petróleo bruto processado e de produtos derivados de petróleo bruto, visando à melhoria da eficiência energética.

Ainda de acordo com a Companhia, algumas iniciativas foram tomadas visando a otimização da gestão de vapor dos geradores, caldeiras e fornos, a melhoria da supervisão operacional e de sistemas de controle, upgrades de equipamentos consumidores de energia, tais como unidades de destilação atmosférica e catalítica e reformadores e a expansão da utilização da cogeração. 
Tabela 4: Resultado do indicador EN8- Total de retirada de água por fonte

\begin{tabular}{|c|c|}
\hline Empresa & \% de Aumento (Redução) da Retirada \\
\hline BP & 55 \\
\hline Chevron & Não divulgado \\
\hline ConocoPhillips & Não divulgado \\
\hline ExxonMobil & 5 \\
\hline Shell & $(14)$ \\
\hline Total & $(36)$ \\
\hline Pemex & $(22)$ \\
\hline Petrobras & 74 \\
\hline
\end{tabular}

Fonte: Adaptado do GRI -2008

Os resultados da Tabela 4 demonstram que das oito companhias analisadas, três (37\%) reduziram, duas (25\%) aumentaram e duas (25\%) não apresentam o indicador de total de retirada de água.

Em 2007, as operações da SHELL consumiram 574 milhões de metros cúbicos de água doce. Isso representa um consumo menor em $17 \%$ quando comparado a 2000 e de aproximadamente $0,01 \%$ do total mundial. A Companhia reforça que está envidando esforços para reduzir a utilização em locais onde a água é escassa.

A Companhia cita como exemplo a Refinaria em Geelong, na Austrália, propensa a funcionar a seco, cujo projeto, consumiu em 2007, US\$ 46 milhões. Essa iniciativa propiciou a redução da utilização por água de 110.000 metros cúbicos por ano, o suficiente para satisfazer as necessidades anuais de mais de 650 famílias em Geelong. As mudanças incluíram recuperação e reutilização do vapor no processo de fabricação e melhoria dos sistemas de detecção e reparação de fugas água.

De acordo com os relatórios de sustentabilidade analisados, a TOTAL constituiu em 2004, um grupo de trabalho específico para estabelecer um programa de redução da utilização da água, que cobre todos os tipos de água. O programa denominado "multi-etapas" compreende uma vistoria e retirada de água em todos os sites da Companhia. Observa-se que uma redução de $36 \%$, foi totalmente obtida entre 2004 e 2006.

Com base nesta experiência, um documento intitulado Otimização do Consumo de Água em instalações industriais, foi emitido em 2007. Este documento foi concebido para partilhar as melhores práticas em todas as unidades da TOTAL, ajudando a definir metas quantitativas, especialmente para aquelas unidades onde a utilização da água em processos industriais concorre com consumo doméstico e agrícola.

A redução do uso de água fresca na PEMEX decorre principalmente do aumento de água tratada que foi reutilizada, principalmente pela PEMEX Refinación, e a conseqüente diminuição no 
uso de fontes de água doce natural (solo, subsolo, mar, água corrente e outros). O uso de água tratada foi aumentado pelo terceiro ano consecutivo (2005 a 2007), atingindo um volume equivalente a $13,4 \%$ do seu consumo total. Cerca de $80 \%$ da água doce utilizada provém de fontes superficiais e subterrâneas. O consumo está concentrado nas atividades industriais.

Adicionalmente, para reduzir o uso de água fresca nas operações das refinarias dos Municípios de Madero e Tampico, está sendo construindo uma planta de tratamento de efluentes com capacidade para 900 litros por segundo, dos quais 600 litros serão destinados a uma utilização industrial da refinaria, que deixará de usar a água fresca. O resto será para utilização nos Municípios de Madero e Tampico, sendo prevista a sua conclusão em 2008.

Durante 2007 a PEMEX empreendeu uma análise das fontes de água para utilização na operação e serviços de todas as suas instalações considerando fatores como crescimento populacional e as expectativas, facilidades e expansões no futuro, as normas nacionais e o acesso às fontes e usos da água nas cidades. Esta análise poderá permitir a identificação de centros capazes de trabalhar utilizando águas residuais tratadas.

Tabela 5: Resultado do indicador EN16- Total de emissões diretas e indiretas de gases causadores do efeito estufa, por peso

\begin{tabular}{|c|c|}
\hline Empresa & $\begin{array}{c}\text { \% de Aumento (Redução) das } \\
\text { Emissões }\end{array}$ \\
\hline $\mathrm{BP}$ & $(21)$ \\
\hline Chevron & $(2)$ \\
\hline ConocoPhillips & 21 \\
\hline ExxonMobil & 3 \\
\hline Shell & (18) \\
\hline Total & $(8)$ \\
\hline Pemex & 10 \\
\hline Petrobras & 28 \\
\hline
\end{tabular}

Fonte: Adaptado do GRI -2008

A tabela 5 apresenta os resultados das oito companhias analisadas, sendo que quatro (50\%) reduziram e quatro (50\%) aumentaram. Observa-se que todas as empresas divulgaram esse indicador no período analisado. BP e SHELL se destacam na redução de emissões diretas e indiretas de gases causadores do efeito estufa. Juntas conseguiram reduzir 39 milhões de toneladas de $\mathrm{CO}_{2}$ equivalentes no período analisado.

A BP tem como objetivo melhorar constantemente seu negócio comercial mediante projetos de eficiência energética. Em 2006 foi alcançada uma redução significativa, tendo sido mantido o número em 2007, graças ao programa sobre eficiência energética de sete anos de duração, onde foram investidos US\$ 450 milhões, iniciado em 2004, o que permitiu um recorde tanto na diminuição dos custos como das emissões de gases de efeito estufa. A Companhia informa que desde 2001, vem realizando acompanhamento do aumento subjacente das emissões de gases do 
efeito estufa procedentes do crescimento da companhia e comparando-o com a redução de emissões alcançadas em todas as operações.

De acordo com os relatórios de sustentabilidade analisados da SHELL, a produção e processamento de petróleo e gás natural é energia intensiva. Segundo a Companhia a gestão do $\mathrm{CO}_{2}$ e outros gases com efeito de estufa (GEE) a partir de suas instalações é uma prioridade. As maiores reduções ocorreram a partir uso contínuo de gás natural nas instalações de produção de petróleo denominadas multibillion-dólar, relacionadas a um programa lançado em 2000. O total de gases de efeito estufa na área de exploração e produção caiu quase 60\% desde 2001. Metade da queda dos gases do efeito estufa é resultado desse programa. O resto vem da redução de produção na Nigéria o que representa dois terços do grande resultado obtido. A Companhia relata ainda que fora da Nigéria, são efetivamente cumpridos os objetivos para por fim a emissão de gases do efeito estufa.

Tabela 6: Resultado do indicador EN20 - NOx, SOx e outras emissões atmosféricas significativas, por tipo de peso:

\begin{tabular}{|c|c|c|}
\hline Empresa & \% de Aumento (Redução) das Emissões \\
\hline & NOx & SOx \\
\hline BP & $(7)$ & $(34)$ \\
\hline Chevron & 15 & $(39)$ \\
\hline ConocoPhillips & 10 & $(40)$ \\
\hline ExxonMobil & $(22)$ & $(21)$ \\
\hline Shell & $(22)$ & $(10)$ \\
\hline Total & 5 & $(4)$ \\
\hline Pemex & 4 & 33 \\
\hline Petrobras & 17 & $(6)$ \\
\hline
\end{tabular}

Fonte: Adaptado do GRI -2008

Analisando os resultados da Tabela 6, verifica-se que apenas três (37\%) companhias reduziram respectivamente as emissões NOx e SOx, enquanto que uma (13\%) teve aumento com essas emissões. Destaque para a EXXONMOBIL que reduziu 110 mil toneladas de NOx e SOx, acompanhada da SHELL com uma redução de 77 mil toneladas e por fim a BP com 68 mil toneladas de redução atmosféricas significativas. As demais companhias apresentam resultados que demonstram aumentos e reduções dessas emissões.

Para a BP algumas emissões decorrentes das suas operações têm impacto potencial na qualidade do ar local, entre elas incluem o dióxido de enxofre, óxidos nitrosos e hidrofluorcarbonos. Segundo a Companhia, com a implementação do seu programa de gestão ambiental (US\$ 20 milhões) para novos projetos em suas refinarias, pretende compreender o impacto que pode ter sobre a qualidade do ar na atmosfera local e regional, de forma que possa evitar, prevenir e reduzir as emissões da atmosfera e mitigar os possíveis efeitos sobre a saúde humana e danos ao meio ambiente dessas emissões. A Companhia pretende ainda investir US\$ 30 milhões em 10 anos para programas de benefícios a comunidade afetada. 
Segundo os relatórios de sustentabilidade analisados, a EXXONMOBIL está trabalhando para reduzir as emissões de compostos orgânicos voláteis dióxido de enxofre $\left(\mathrm{SO}_{\mathrm{x}}\right)$ e óxido nitroso $\left(\mathrm{NO}_{\mathrm{x}}\right)$ em suas operações.

A Companhia tem implementado custo-eficácia das novas tecnologias e novas práticas operacionais adotadas para a redução das emissões atmosféricas, impulsionado em parte pelas novas exigências regulamentares, mas também em resposta às prioridades da comunidade. Como resultado desses esforços, as emissões combinadas de $\mathrm{SO}_{\mathrm{x}}$ e, $\mathrm{NO}_{\mathrm{x}}$ diminuíram a níveis de 2004.

A Companhia vem atualizando continuadamente instalações de produção nos Estados Unidos, para atingir a meta de reduzir de forma combinada as emissões de $\mathrm{NO}_{\mathrm{x}}$ e $\mathrm{SO}_{\mathrm{x}}$ em cerca de $70 \%$ a partir de 2000 seu nível básico. No final do ano 2007, a Companhia alcançou entre 50\% e os $60 \%$ do seu objetivo de redução. Em todos os sites das refinarias nos Estados Unidos observa-se a implantação de algumas medidas de redução e continuam fazendo outras atualizações, tais como upgrades e melhorias para a instalação do ar, que incluem a redução das emissões de $\mathrm{NO}_{\mathrm{x}}$, a instalação de processos de recuperação de enxofre e do gás adicional queimado.

De acordo com os relatórios de sustentabilidade analisados, a contribuição da SHELL começa com a redução das emissões a partir de suas instalações, que contribuem para o nevoeiro e chuva ácida - o óxido nitroso $\left(\mathrm{NO}_{\mathrm{x}}\right)$, dióxido de enxofre $\left(\mathrm{SO}_{2}\right)$ e orgânicos voláteis Compostos $(\mathrm{COV})$.

Segundo a Companhia as emissões de $\mathrm{NO}_{\mathrm{x}}$ são mais baixas, por estarem usando no momento mais energia limpa para refinar combustíveis. Isto se deve principalmente a investimentos em equipamentos de controle de poluição, especialmente nas refinarias e plantas de produtos químicos em Cingapura e nos Estados Unidos.

Quanto às emissões de $\mathrm{SO}_{\mathrm{x}}$, estas têm aumentado, principalmente porque o gás está sendo deflagrado em locais remotos no Canadá e Omã. Com a ajuda da Companhia, pessoas que vivem perto de alguns desses sites, passaram a participar do controle da qualidade do ar nessas comunidades.

Portanto, aumentar a produção de gás natural combustível para essas instalações contribuirá para a redução dessas emissões no ar; o mesmo acontece com a tecnologia de gaseificação do carvão, que reduzirá drasticamente a poluição local a partir de centrais elétricas a carvão que são geradas através da conversão do carvão para um sintético de gás que queima tão limpo quanto gás natural. A utilização do vento e a energia solar também podem ajudar a SHELL a acelerar o crescimento dessas fontes de emissão zero. 
Tabela 7: Resultado do indicador EN22 - Peso total de resíduos, por tipo e método de disposição:

\begin{tabular}{|l|c|}
\hline \multicolumn{1}{|c|}{ Empresa } & \% de Aumento (Redução) de Resíduos \\
\hline BP & $(1)$ \\
\hline Chevron & Não divulgado \\
\hline ConocoPhillips & 1040 \\
\hline ExxonMobil & $(57)$ \\
\hline Shell & 153 \\
\hline Total & 10 \\
\hline Pemex & 21 \\
\hline Petrobras & $(44)$ \\
\hline
\end{tabular}

Fonte: Adaptado do GRI -2008

Os resultados apresentados na Tabela 7 demonstram que apenas três (37\%) das oito companhias apresentam redução de produção de resíduos gerados, representando 460 mil toneladas. Destaque para EXXOMOBIL e PETROBRAS, que juntas reduziram 99,8\% do total mencionado acima.

A EXXOMOBIL não divulgou em 2003, o indicador referenciado, desse modo, a análise do desempenho do indicador foi realizada para o período de 2004 e 2007. A Companhia apresentou redução de $57 \%$ na emissão de resíduos, correspondendo a 223 mil toneladas. Essa redução vem sendo obtida a partir de 2004, onde se observa a maior redução (97 mil toneladas).

De acordo com seus relatórios de sustentabilidade, a Companhia utiliza uma abordagem escalonada para reduzir tanto os resíduos não perigosos e perigosos. Se o resíduo não é totalmente eliminado, usa-se a reciclagem e a reutilização dos materiais quando possível.

Qualquer resíduo restante é tratado para torná-lo não perigoso ou eliminado em conformidade com as regulamentações locais. Ao longo dos últimos cinco anos, a Companhia teve êxito, reutilizando ou reciclando, em média, cerca de $40 \%$ dos resíduos perigosos gerados.

Além disso, a EXXONMOBIL desenvolveu uma norma ambiental para a gestão de resíduos para utilização na concepção de projetos importantes. Esta norma estabelece o ciclo completo do planejamento do projeto e a gestão de resíduos.

De acordo com os relatórios de sustentabilidade analisados, a PETROBRAS utiliza critérios legais e internos para limitar a carga de óleos e graxas lançada pelos efluentes de todas as instalações da Companhia.

Segundo a Companhia todas as unidades operacionais têm sistemas de tratamento de efluentes e, periodicamente são melhorados à medida que se desenvolvem novas práticas de gestão de água e efluentes ou quando surgem novas restrições de ordem legal. Para o tratamento de resíduos, destaca-se o incentivo às alternativas de reaproveitamento, onde os resíduos abatidos foram destinados ao reuso como combustível alternativo em fornos e/ou reciclados. 
Por fim, a Companhia informa que não foram transportados, importados, exportados ou tratados resíduos considerados perigosos nos termos da Convenção da Basiléia sobre o Controle de Movimentos Fronteiriços de Resíduos Perigosos e seu Depósito, bem como não houve transporte internacional de resíduos.

A partir de 2008, as informações qualitativas e quantitativas sobre o descarte de efluentes na PETROBRAS passam a ser acompanhadas e consolidadas corporativamente de forma sistematizada e rastreável.

Tabela 8: Resultado do indicador EN23 - Número e volume total de derramamentos significativos

\begin{tabular}{|l|c|c|}
\hline \multicolumn{1}{|c|}{ Empresa } & \multicolumn{2}{c|}{$\begin{array}{c}\text { \% de Aumento (Redução) } \\
\text { derramamentos }\end{array}$} \\
\hline & Número & Volume \\
\hline BP & $(46)$ & $(75)$ \\
\hline Chevron & $(28)$ & $(67)$ \\
\hline ConocoPhillips & $(12)$ & $(27)$ \\
\hline ExxonMobil & $(46)$ & $(64)$ \\
\hline Shell & 60 & 0 \\
\hline Total & 330 & 400 \\
\hline Pemex & 48 & 23 \\
\hline Petrobras & Não divulgado & $40 \%$ \\
\hline
\end{tabular}

Fonte: Adaptado do GRI -2008

Das oito companhias analisadas na Tabela 8, quatro (50\%) tiveram redução nas duas medidas do indicador, três (37) aumentaram, sendo que a PETROBRAS só passou a divulgar o número de derramamentos a partir de 2007. A redução do volume total de derramamentos das quatro companhias foi de 61 mil barris de petróleo, tendo destaque para BP e CHEVRON com 18 e 17 mil barris de petróleo respectivamente.

Segundo os relatórios de sustentabilidade analisados, a BP vem tomando medidas para resolver vários assuntos específicos relacionados com a integridade física das plantas e dos oleodutos, que inclui inspeções e testes de equipamentos de segurança, procedimentos operacionais e treinamento de empregados e o monitoramento do número acidentes.

A Companhia informa ainda que também contribuíram para essas reduções a eficácia das operações de refino e comercialização, superando o objetivo de redução de $10 \%$ anuais, bem como outras operações que lograram os objetivos planejados. A Companhia investirá mais de US\$ 550 milhões na gestão da integridade nas operações realizadas no Alaska (inspeção dos sistemas de transporte de óleo bruto em Prudhoe Bay) durante os próximos anos, já considerados US\$ 200 milhões, investidos em 2007.

De acordo com os relatórios de sustentabilidade analisados, a CHEVRON Companhia vem melhorando a partir de 2005, o seu desempenho com o número e o volume total de derramamentos. 
Em 2004, os derramamentos foram relacionados ao furacão. A Companhia não forneceu em seus relatórios maiores detalhes sobre a evolução do indicador.

Segundo a CONOCOPHILLIPS a Companhia tem uma resposta de emergência global através de um processo integrado, que inclui a capacidade de resposta e de planos de gestão de crises no âmbito corporativo, regional e local. Todos os planos contemplam treinamentos regulares, manutenção de equipamentos e revisão de procedimentos. A Companhia participa de cooperativas que abrangem organizações que proporcionam assistência imediata a emergências que se estendam à comunidade.

De acordo com os relatórios de sustentabilidade analisados, a EXXONMOBIL está empenhada na prevenção de derrames de suas operações e é líder da indústria em prevenção de derramamentos. Esse desempenho é resultado da contínua modernização de instalações, substituições de equipamentos chaves e uma inspeção exaustiva e programas de vigilância.

\section{Conclusões}

A Avaliação do Desempenho Ambiental da Indústria constitui o meio para mensurar a eficácia dos procedimentos de conservação e/ou otimização do uso dos recursos naturais, bem como das medidas de controle ambiental adotadas, ou a serem adotadas, pelas companhias.

Sua implementação é pautada no uso de indicadores ambientais, descritos e comentados nesse estudo, e são relativas a todos os esforços de gestão da empresa que influenciam positivamente no seu desempenho ambiental.

O estudo revelou que cada vez mais, as companhias petrolíferas estão empenhadas em simplificar e racionalizar seus processos internos, modificando projetos e implantando programas privilegiando as questões ambientais.

Hoje, as companhias de petróleo reconhecem que a excelência nas praticas referentes ao meio ambiente é um dos componentes da estratégia de criação de valor duradouro. Isso se reflete no aumento em investimentos relacionados com a questão ambiental, decorrentes das necessidades de mudanças significativas nos padrões de produção, comercialização e consumo. Estas mudanças respondem a normas e dispositivos legais rígidos de controle (nacionais e internacionais), associados a um novo perfil de consumidor. É fundamental que as empresas busquem uma relação harmônica com o meio ambiente, mediante a adoção de práticas de controle sobre os processos produtivos e o uso de recursos naturais renováveis e não renováveis.

A análise ratifica a força da indústria petrolífera como indutora de um novo modelo de negócio e define que as companhias realmente comprometidas com um futuro sustentável, são aquelas que buscam mudanças de cultura interna de gestão para consolidar a sustentabilidade em 
sua estratégia, realizando investimentos adequados aos desafios da sustentabilidade e que atuam na conscientização ambiental de seus colaboradores, clientes, parceiros de negócios e das comunidades instaladas próximas a suas unidades produtivas.

\begin{abstract}
The research covers the verification of the illustration degree of the environment sustainability indicators The selected for this study (consolidated per year) and reported by these companies, but also presents the main practices adopted from the petroleum corporations selected to the research that has been taking to a likely increase of their environmental performance.
\end{abstract}

Key-words: indicators; sustainability; petroleum.

\title{
Referências
}

AMARAL, Sergio Pinto. Estabelecimento de indicadores e modelo de relatório de sustentabilidade ambiental, social e econômica: uma proposta para a indústria de petróleo brasileira. Rio de janeiro: Universidade Federal do Rio de Janeiro; 2003. 1v.

ARAGAO, Amanda Pereira, Estimativa da contribuição do setor petróleo ao produto interno bruto brasileiro: 1995/2004. Dissertação (Mestrado em Planejamento Estratégico). Rio de Janeiro: COPPE/UFRJ, 2005.

BELLEN, Hans Michael V. Indicadores de Sustentabilidade: Uma análise comparativa Rio de Janeiro: Editora FGV, 2006. 253 p. (2006).

BOSSEL, H. Indicators for sustainable development: theory, method, applications: a report to the Balaton Group. Winnipeg: IISD, 1999.

COMISSÃO MUNDIAL SOBRE MEIO AMBIENTE E DESENVOLVIMENTO. Nosso futuro comum.2. Ed. Rio de Janeiro: Fundação Getúlio Vargas, 1991. 430 p.

IBGE. Indicadores de desenvolvimento sustentável. Rio de Janeiro. 2002. n. 2. 195 p.

FERRAZ, J. M. G. in PEDREIRA, JOSE CARLOS - Caminhos da sustentabilidade no Brasil. Terra das Artes Editora. São Paulo, p. 223, 2005

PEDREIRA, JOSE CARLOS - Caminhos da sustentabilidade no Brasil. Terra das Artes Editora. São Paulo, p. 222, 2005.

PETROLEUM INTELLIGENCE WEEKLY 2007.

ROMEIRO, Ademar Ribeiro. "Economia ou Economia Política da Sustentabilidade", in: MAY, Peter H., Maria Cecília Lustosa \& Valéria da Vinha (orgs.) Economia do Meio Ambiente; Teoria e Prática. Rio de Janeiro: EcoEco \& Editora Campus, 2003, pp. 1-29.

VERGARA, S. C. Projetos e Relatórios de Pesquisa em Administração. 5. ${ }^{a}$ ed. São Paulo: Editora Atlas, 2004.

YIN, Robert K. Estudo de caso: planejamento e métodos. 2. ${ }^{\text {a }}$ ed. Porto Alegre: Bookman, 2001.

Websites

http://www.exxonmobil.com/Corporate/community_ccr_archive.aspx

http://www.conocophillips.com/social/index.htm

http://www.shell.com/home/content/responsible_energy/sustainability_reports/dir_shell_sustainability_reports.html 
http://www.pemex.com/index.cfm?action=content\&sectionID=3

http://desarrollosustentable.pemex.com/portal/index.cfm?action=content\&sectionID=2\&catID=681

http://www.total.com/en/corporate-social-responsibility/

http://www.bp.com/productlanding.do?categoryId=6913\&contentId=7043155

http://www.chevron.com/globalissues/corporateresponsibility/2007

http://www2.petrobras.com.br/portal/frame.asp?pagina=/ResponsabilidadeSocial/portugues/index.asp\&lang=pt\&area=r $\underline{\mathrm{sa}}$

http//eee.globalreporting.org>

\section{DADOS DOS AUTORES}

Nome completo: Antonio Roberto da Silva

Filiação institucional: Petrobras

Departamento; Contabilidade

Função ou cargo ocupado: Gerente de Planejamento Contabil

Endereço completo: Rua Antonio Basilio 176, ap 502 - Tijuca - CEP 20511-190 - Rio de Janeiro - RJ

telefones para contato: 3224-1431 ( Comercial), 9997-6336, 2571-8008 (Res)

e-mail: arsilva@petrobras.com.br

Nome completo: Stella Regina Reis da Costa

Filiação institucional: Universidade Federal Fluminense e Universidade Federal Rural do Rio de Janeiro

Departamento: LATEC e Departamento de Tecnologia de Alimentos

Função ou cargo ocupado: Professora Titular

Endereço completo para correspondência (bairro, cidade, estado, país e CEP): Travessa dos Tamoios, Flamengo, Rio de Janeiro, RJ, Brasil, CEP:22230-050

Telefones para contato:

e-mail: stellare@ig.com.br 